\title{
AN INTELLIGENT SELF-ADAPTIVE SYSTEM TO AUTOMATE THE SPRINKLER CONTROL
}

\author{
Jiahao Li ${ }^{1}$, Yu Sun ${ }^{2}$, Fangyan Zhang ${ }^{3}$ \\ ${ }^{1}$ Northwood High School, Irvine, CA, USA \\ ${ }^{2}$ Department of Computer Science, \\ California State Polytechnic University, Pomona, CA, USA \\ ${ }^{3}$ Department of Computer Science and Engineering, \\ Mississippi State University
}

\begin{abstract}
It has been seven years since California is in serious drought. The dam holds rare water, and for some area the plants and people are suffered. While the technologies of desalination and reusing water is improving, it is significant if we solve the problem from the root, which is reducing water usage and saving water. Since eighty percent of water in California is used for agriculture and greening, it is efficient if we break through the system of irrigation. Currently, there are many ways to reduce watering in agriculture such as dropping water drops from pipes instead of spraying water; however, there are now resolution addressing the system of private watering yard in communities. The sprinkler device that we designed can contribute to reduce the water that is sprayed through sprinkler by adjusting the status of sprinklers (turning on or turning off) base on real-time weather conditions (temperature and soil humidity). Our purpose is to reduce the spraying water as much as possible if the weather condition allowed.
\end{abstract}

\section{KEYWORDS}

Sprinkler, Smart Control, Mobile App, Water Saving

\section{INTRODUCTION}

According to United States Geological Survey (USGS) [5], "As of May 23, 2017, the National Drought Mitigation Center estimates approximately 10.3 million people in California are currently affected by the drought." In fact, California has been in drought for many years and the condition is getting worse and worse. Figure 1 shows that in recent record, still most of area in California suffers from shortage of water especially large city such as Los Angeles. Based on the current condition of drought, it is necessary for every resident of California to save water. With the rapid development of computer science and particularly Internet-Of-Things [6], it is possible to use technology to solve this problem in practice. Based on the fact that a lot of residents have to adjust the time of watering in our backyard very based on weather frequently [7][8], we decided to think about saving water resources though reducing unnecessary watering in every of these situations. In order to achieve the goal of reducing watering while keeping the plants healthy, we have designed and developed a sprinkler system that can adapt to the actual environment and be capable of turning on and off automatically according to the temperature and humidity in soil. Using this device, people do not need to worry about wasting water every time the sprinkler can automatically turn on or off the sprinkler system based on the real need.

Natarajan Meghanathan et al. (Eds) : ICCSEA, WiMoA, SPPR, GridCom, CSIA - 2017

pp. 171- 176, 2017. @ CS \& IT-CSCP 2017

DOI : $10.5121 /$ csit.2017.71114 
At present, people rarely pay attention to sprinkler all the time and they will not water the grass by hands, they simply set up the timer so the sprinklers can spray water automatically during certain period of the time. However, during this process, huge amount of water is wasted due to unnecessary watering in cool wet autumn evening. Thus, it is crucial to build an irrigation system that can save the whole process for people.
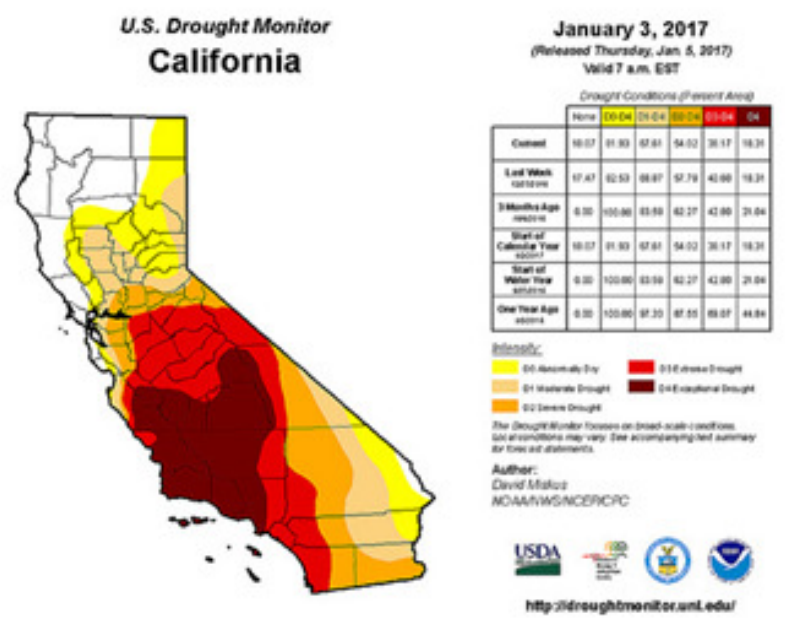

Figure 1: The U.S. Drought Monitor of drought situation of California in 2017 (adapted from [9])

To solve the issue, we have developed an intelligent smart irrigation system that contains two major components: 1) the Internet-Of-Things (IoT) system that uses temperature and humidity sensors to detect the actual soil environment data and send the real-time data back to the controller, where the smart decision will be made based on the data received; 2) A mobile app, "Servant Sprinkler", would receive the real-time data and present them on the screen, which is easier for users to monitor the temperature and humidity since they can also turn on or off the sprinkler by hands.

The rest of the paper is organized as follows: Section 2 gives the details on the challenges that we met during the experiment and designing the sample; Section 3 focuses on the details of our solutions corresponding to the challenges that we mentioned in Section 2; Section 4 presents the relevant details about the experiment we did, following by presenting the related work in Section 5. Finally, Section 6 gives the conclusion remarks, as well as pointing out the future work of this project.

\section{Challenges}

In this section, we discuss three challenges that confront us as we design the smart irrigation system. They are including accurate data collection, proper threshold setting, and effective interactions.

\subsection{Challenge 1: Data Collection}

The top one challenge is how to receive real-time data. If the operation of the device is totally depending on the weather report, it is useless. It is also impossible to collect data from several years and create a specific function to predict the future weather. Because there are different weather conditions in different areas and the sprinkler need to adjust itself base on weather condition, we need a device that can collect local environmental data constantly and present it to. 


\subsection{Challenge 2: Threshold Setting}

The second challenge is that we needed to deal with how to set up the standards for both temperature and humidity, which are the values that sprinkler will shut down automatically if the they are reached. Since the device mainly depends on the adjusting itself, it is crucial to set up relatively perfect standards to maximize the effort. If the standards are too high, the plants would die before the sprinklers are triggered to spray water; if the standards are too low, the situation of wasting water is still not solved. The research is needed for deciding the standards carefully.

\subsection{Challenge 3: Interactions}

The third challenge is how to make users interact with the device effectively and smoothly. As we all known, technology cannot replace human totally. There is probability that some tiny errors will occur, so human involvement is necessary. In this case, there might be some extreme weather that the temperature is low and the soil humidity is extremely low as well, which will not trigger the switch of sprinkler and the plants might suffer low temperature and poor moisture in the soil. This is the reason that the users need to know the real-time condition constantly. Since there is neither screen on the device nor a computer that is connected to it, it is necessary to visualize these codes to data, then to the sentence that people can read. Also, since it is not realistic for users to stay aside a computer to read the data, a moveable controller is needed which can show the meaning of data, temperature and humidity, and be manipulated by people at any time.

\section{SMART SPRINKLER IN ACTION}

To solve the above three challenges, we have developed a smart control device that can manipulate if there is water comes out or not automatically. As shown in Figure 2, the system contains two modules: the receiver that receives all data about humidity and temperature from sensors while is connecting to a Bluetooth launcher built with Arduino [11], which is connected to a Raspberry PI as the main controller [12]. The second module of the system is a power switch connecting to the main Raspberry PI controller. The controller is designed to revive the data through Firebase database, whose data is stored in Google Cloud. There is a program that we wrote in the Raspberry PI, which tells when to stop or release the water and spray to grass.

As it comes to collecting real-time data on temperature and humidity, one feasible solution is to send the data from sensors to cloud, which can be monitored through phone app. Since people may be out of home for most of the day time, it is nearly impossible to go to yard and keep paying attention of the data on sensor all the time, we develop an app that comes with the device. We upload the data from sensors to Firebase [10], then develop an app which can receive the data from computer and show it on the screen. Firebase is a cloud-based data synchronization and communication system that could be used to ease the data transfer across multiple devices and clients. Through this method, people are able to know the accurate temperature and humidity in their backyards.

On the other hand, a proper threshold to turn on or off the device has been tested and configured in order to enable the automated control. To accomplish that, we prepared two sensors for temperature and humidity; then wrote a program which gave orders to turn on the switch as long as the certain values are reached. Based on the special location of California, we set the limits as 24 Celsius degrees for temperature and $50 \%$ as moisture. Since the sunlight that strikes on the ground of California is relatively strong, the moisture is easier to evaporate, which is deal with by setting the standard for humidity as 50\%. The highest average for Long Beach in 2010 was $29^{\circ} \mathrm{C}$, it is important for plants to receive sufficient water under high temperature and direct sunlight striking. 
Temperature and Humidity Sensor
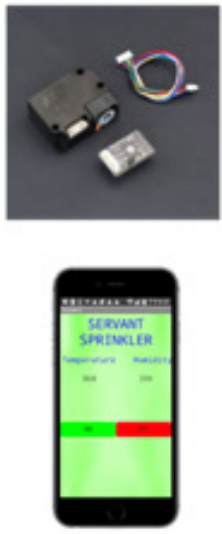

Mobile App
Arduino
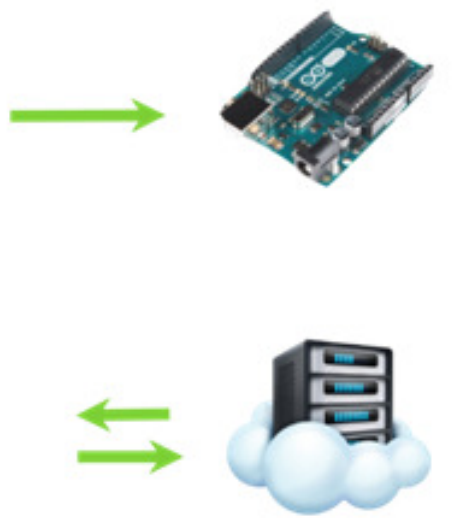

Google Cloud Server
Raspberry PI
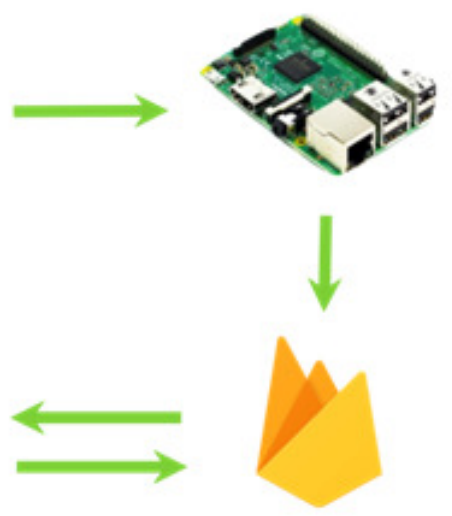

Firebase Database

Figure 2. An Overview of the System

Finally, in order to address the challenge of how to interact with humans in case some extreme weather occurs, we decided to upload all the data from sensors to Firebase. There are already two sensors on the main board, and we added another element, which is a Bluetooth launcher. The data collected by the sensors will be launched to a cloud center call Firebase which could receive and store all the data. Then, a mobile app, Servant Sprinkler as shown in Figure 3, is developed for receiving the data from Firebase. In there, there are two blocks, one showing current temperature and the other one showing current soil humidity. This corresponding mobile app is a convenient tool for users to observe the real-time data. Besides that, there are two buttons, named "turn on" and "turn off", can be used to activate or shut down the system by hands. If there are some kind of extreme weather with low temperature and low humidity, the users can manipulate the sprinkler and amount of water sprayed to grass base on their own wish instead of rely on technology only.

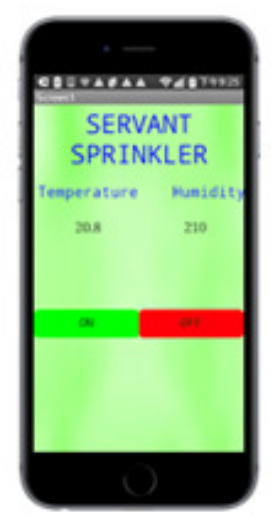

Figure 3. The Servant Sprinker Mobile Controller App

\section{EVALUATION OF SMART IRRIGATION SYSTEM}

In order to accomplish this goal, the amount of water that is saved is the essential standard for evaluating the value of putting this product into market. Base on the observation, each neighborhood's sprinklers sprays water for three minutes continuously. For average residential 
sprinkler for lawn, each minute the water usage is about 1-6 gallons. Every day the sprinkler spray water at eight o'clock in the evening for three minutes, which tells that the sprinkler spray 54 gallons of water averagely. There are 150 houses in my community, which means that each day the water usage is 8100 gallons of water. However, based on the fact that there are approximately 20 percent of the days that the outside temperature is lower than 24 Celsius degrees and 7 percent that the humidity is higher than 50 percent as shown in Table 1, which means that over 30 days the sprinklers ignore the rain and spray the unnecessary water anyways, which is a total kind of waste. In my community, the spraying time is exactly three minutes at 8 pm every day, which is not reasonable because the cool weather will evaporate less water as it would during noon. After observation, each day one sprinkler in my yard sprays total of 5 gallons of water, which is the same for every sprinkler in my community. After connect the device to the sprinkler, my sprinkler sprayed total of 21 minutes per week per family, which means there is 35 gallons of water is used by one sprinkler. If the probability of weather lower than 24 Celsius degrees and humidity under 50 percent is 14 percent of time, there are 4.9 gallons of water is wasted in yard while there is a water shortage in California dam. After communicating with a Chinese factory, we made improvements about our device. We used their database as a basic stage for receiving and analyzing data. We further improved the device through designing and producing the packing of it and made it more like a mature product.

Table 1: The average Los Angeles temperature [14]

\begin{tabular}{|c|c|c|c|c|}
\hline High $^{\circ} \mathrm{F}$ & Low $^{\circ} \mathbf{F}$ & Month & High ${ }^{\circ} \mathrm{C}$ & Low ${ }^{\circ} \mathrm{C}$ \\
\hline 68 & 48 & January & 20 & 9 \\
\hline 69 & 49 & February & 20 & 10 \\
\hline 70 & 51 & March & 21 & 11 \\
\hline 73 & 54 & April & 23 & 12 \\
\hline 75 & 57 & May & 24 & 14 \\
\hline 78 & 60 & June & 26 & 16 \\
\hline 83 & 64 & July & 28 & 18 \\
\hline 84 & 64 & August & 29 & 18 \\
\hline 83 & 63 & September & 28 & 17 \\
\hline 79 & 59 & October & 26 & 15 \\
\hline 73 & 52 & November & 233 & 11 \\
\hline 68 & 48 & December & 20 & 9 \\
\hline 75 & 56 & Year & 24 & 13 \\
\hline
\end{tabular}

\section{RELATED WORK}

Sprinkler irrigation, distributing water by spraying it over the fields, has been applied for several decades. The water is sprayed from nozzles under the force of water pressure. [1] introduced sprinkler irrigation system and how to choose proper equipment. In order to deliver water to crops more effectively, there are several the study about sprinkler irrigation system. For example, [2] talked about how to formulate and solve mathematical expressions for the application depths and rates from a self-propelled, center-pivot sprinkler irrigation system. [3] proposed a method for evaluating the water application rate and uniformity coefficient of overlapping irrigation sprinklers. [4] conducted a research on relation between non-uniform sprinkler irrigation and crop yield. All these studies aimed to distributed water evenly then obtain better crop yield. None of 
the studies involves saving water by improving sprinkler based the current temperature and humidity in soil.

\section{CONCLUSION AND FUTURE WORK}

In this paper, we present a practical solution to manipulate the switch automatically with a selfadaptive computer program that sets up the standards for the device to enable the water or not. As we can see from the device and the results of the experiment, the system effectively saves water everyday, offering an intelligent approach for users to manage the irrigation. As for the future work, the experimental design can be improved by replacing Bluetooth with other launcher since Bluetooth will be blocked by walls sometimes. Another direction to work on in the future is to enable sharing the data with the local community, so that a large dataset can be built. Using the dataset, models could be trained using machine learning techniques [13] which could be used to guide the all residents no matter whether they have the smart irrigation system or not.

\section{REFERENCES}

[1] Pair, Claude H. "Sprinkler irrigation." (1970).

[2] Heermann, Dale F., and Paul R. Hein. "Performance characteristics of self-propelled center-pivot sprinkler irrigation system." Transactions of the ASAE 11, no. 1 (1968): 11-0015.

[3] Fukui, Y., K. Nakanishi, and S. Okamura. "Computer evaluation of sprinkler irrigation uniformity." Irrigation Science 2, no. 1 (1980): 23-32.

[4] Stern, Jack, and Eshel Bresler. "Nonuniform sprinkler irrigation and crop yield." Irrigation Science 4, no. 1 (1983): 17-29.

[5] USGS California Water Science Center, https://ca.water.usgs.gov/data/drought/

[6] Xia, Feng, et al. "Internet of things." International Journal of Communication Systems 25.9 (2012): 1101.

[7] Caswell, Margriet, and David Zilberman. "The choices of irrigation technologies in California." American journal of agricultural economics 67.2 (1985): 224-234.

[8] Levy, Yvonne. "Pricing federal irrigation water: A California case study." Economic Review Spr (1982): 35-55.

[9] U.S. Drought Monitor. http://droughtmonitor.unl.edu/

[10] Google Cloud Firebase. https://firebase.google.com/

[11] Faludi, Robert. Building wireless sensor networks: with ZigBee, XBee, arduino, and processing. " O'Reilly Media, Inc.", 2010.

[12] Richardson, Matt, and Shawn Wallace. Getting started with raspberry PI. " O'Reilly Media, Inc.", 2012.

[13] Pedregosa, Fabian, et al. "Scikit-learn: Machine learning in Python." Journal of Machine Learning Research 12.Oct (2011): 2825-2830.

[14] U.S. Climate Data. http://www.usclimatedata.com/climate/los-angeles/california/unitedstates/usca1339 